\title{
Adverse effect profile of Lidocaine injections for occipital nerve block in occipital neuralgia
}

\author{
Soma Sahai-Srivastava • Dawood Subhani
}

Received: 10 May 2010/ Accepted: 9 July 2010/Published online: 28 July 2010

(C) Springer-Verlag 2010

\begin{abstract}
To determine whether there are differences in the adverse effect profile between 1,2 and 5\% Lidocaine when used for occipital nerve blocks (ONB) in patients with occipital neuralgia. Occipital neuralgia is an uncommon cause of headaches. Little is known regarding the safety of Lidocaine injections for treatment in larger series of patients. Retrospective chart analysis of all ONB was performed at our headache clinic during a 6-year period on occipital neuralgia patients. 89 consecutive patients with occipital neuralgia underwent a total of 315 ONB. All the patients fulfilled the IHS criteria for Occipital Neuralgia. Demographic data were collected including age, gender, and ethnicity. The average age of this cohort was 53.25 years, and the majority of patients were females 69 $(78 \%)$. Ethnicity of patients was diverse, with Caucasian 48(54\%), Hispanics 31(35\%), and others 10 (11\%). 69 patients had $1 \%, 18$ patients had $2 \%$ and 29 patient were given 5\% Lidocaine. All Lidocaine injections were given with $20 \mathrm{mg}$ Depo-medrol and the same injection technique and location were used for all the procedures. Eight patients $(9 \%)$ had adverse effects to the Lidocaine and Depo-medrol injections, of which 5 received $5 \%$ and 3 received $1 \%$ Lidocaine. Majority of patients who had adverse effects were female $7(87 \%)$, and had received bilateral blocks (75\%). ONB is a safe procedure with $1 \%$ Lidocaine; however, caution should be exerted with $5 \%$ in elderly patients, 70 or older, especially when administering bilateral injections.
\end{abstract}

S. Sahai-Srivastava $(\bowtie) \cdot$ D. Subhani

Department of Neurology, Keck School of Medicine,

University of Southern California, 1100 North State St,

Room A4E111, Los Angeles, CA 90033, USA

e-mail: sahai@usc.edu
Keywords Occipital neuralgia · Adverse effects · Lidocaine - Occipital nerve block

\section{Introduction}

Occipital nerve blocks (ONB) have generated great interest among headache specialists recently because of their potential to treat many types of intractable headaches [1, 2]. Injections are performed by targeting the greater occipital nerve (GON), derived from the dorsal ramus of the second cervical nerve root, which exits the back of the head. It is a relatively uncommon procedure, and recently literature has been emerging on the efficacy of this procedure for various types of headaches. However, even less is known about the adverse effect profile of this procedure. Neuropathic pain in the back of the head along the distribution of the occipital nerves is called Occipital neuralgia [3] and one of the criteria for diagnosis is response to ONB. Occipital neuralgia may be associated with migraine headaches complicating the picture of a chronic daily headache patient $[4,5]$.

In this study, we proposed to investigate whether there were differences in the side effect profile between different strengths of Lidocaine and whether there was a specific population that was more likely to have side effects. To our knowledge, this is the first study reporting on the side effect profile of 5\% Lidocaine for ONB in a large case series of patients.

\section{Methods}

The study sample consisted of retrospective chart review of 89 consecutive patients presenting to our headache clinic at 
the University of California during 2005 to January 2010 with occipital neuralgia as determined by the International headache society criteria (IHS). The IHS criteria for occipital neuralgia include: (1) unilateral headache, continuous or paroxysmal, (2) diminished sensation or dysesthesia in the affected area, (3) circumscribed tenderness over the GON as it crosses the superior nuchal line, (4) relief of acute attack by local anesthetic blocks [6]. The study was approved by the Institutional Review Board of University of Southern California. Demographic data were collected including age, gender, and ethnicity.

All procedures were done using the same landmarks and technique. Injections were performed at the junction of medial and middle thirds from a line drawn between the mastoid process and the nuchal line and the procedure was performed by the same clinician. Vital signs were taken prior to the procedure. All patients had tenderness over GON. Patients with adverse events (AEs) were monitored after the procedure.

\section{Statistical analysis}

We defined a set of clinical and demographic factors that may potentially be associated with $\mathrm{AE}$ and that were available from chart review. Besides patient demographic information (age, gender, and ethnicity), we collected data on the location of ONB (whether unilateral or bilateral) and the number of times ONB was given to each patient. Samples $t$ test was performed to determine correlation analyses between Lidocaine dose and occurrence of AEs and age. Chi-square test was performed to determine correlation analyses between occurrence of AEs and noncontiguous variables. All statistical testing was performed at a two-sided 5\% level of significance using Statistical Analysis System version 11.1 (SAS Institute, Cary, NC).

\section{Results}

There was no difference in age, gender or ethnicity among patients who received 1, 2 or 5\% Lidocaine (Table 1). The majority of patients were middle-aged females. Many of our subjects received serial blocks over the 6-year period, so the total number of blocks performed was much greater than the total number of subjects. Five patients who received Lidocaine 5\% (5/111) and three patients who received (3/173) Lidocaine $1 \%$ reported side effects (Table 2). The majority of patients with AEs received bilateral blocks $(6 / 8)$ and all except one were female. Of those with AEs, $50 \%$ were elderly. One patient with history of pseudoseizures had a typical episode after 5\% Lidocaine and an electroencephalogram done during the episode showed no evidence of epileptic activity. Three patients
Table 1 Demographics

\begin{tabular}{llll}
\hline & $\begin{array}{l}1 \% \\
\text { Lidocaine }\end{array}$ & $\begin{array}{l}2 \% \\
\text { Lidocaine }\end{array}$ & $\begin{array}{l}5 \% \\
\text { Lidocaine }\end{array}$ \\
\hline No. of subjects & 69 & 18 & 29 \\
Total no. of blocks & 173 & 31 & 111 \\
Unilateral & 51 & 13 & 17 \\
Bilateral & 61 & 9 & 47 \\
Age in years, mean (SD) & $53(19)$ & $58.2(17.5)$ & $50.3(19.7)$ \\
Female, no. (\%) & $54(78)$ & $15(83.3)$ & $19(79)$ \\
Race, no. (\%) & & & \\
$\quad$ White & $35(51)$ & $8(44)$ & $19(66)$ \\
Hispanic & $25(36)$ & $7(39)$ & $6(21)$ \\
African American & $2(0.03)$ & $3(17)$ & $4(14)$ \\
Asian & $7(10)$ & 0 & 0 \\
\hline
\end{tabular}

given 5\% Lidocaine reported dizziness and elevation in blood pressure compared to the pre-procedural measurement. Our 71-year-old female had the most significant elevation in BP from 133/71 at baseline, to 209/84, which came back to normal levels (129/90) almost $2 \mathrm{~h}$ after the procedure. Our 73-year-old subject recorded a baseline BP of $114 / 69$, which after the procedure (during her pseudoseizure), was elevated to 140-150/70 transiently, but resumed normal values within $45 \mathrm{~min}$. Our third patient had a minor elevation in blood pressure only. None of the patients injected $1 \%$ Lidocaine had any elevation in blood pressure.

We report no statistically significant correlation between Lidocaine dose and occurrence of adverse effects, though there was a slight trend toward more adverse effects in the Lidocaine 5\% group $(p=0.072)$ compared to the Lidocaine $1 \%$ group $(p=0.33)$. There was no significant correlation between the occurrence of AEs and age, gender or bilateral versus unilateral injections. All our subjects, including those who had side effects reported complete pain relief for at least 3-7 days, the maximum period of pain relief being 33 days.

\section{Discussion}

To our knowledge, this is the first report comparing 1,2 and 5\% Lidocaine use in a homogenous group of patients with a single diagnosis and where the same type of injection and steroid was used for all the procedures. Ours is the first large case series report of experience with 5\% Lidocaine for ONB. Choi et al. [7] were the first to describe the use of 5\% Lidocaine for ONB and suggested that it may have a more long-lasting effect than 1 or $2 \%$ injections. Choi et al. study did not report on any side effects and their sample size was very small. No other authors have reported 
Table 2 Adverse effect description for 1,2 , and $5 \%$ Lidocaine

\begin{tabular}{clll}
\hline Age & Sex & Side & Side effect description \\
\hline $5 \%$ Lidocaine & & R & Dizziness, blurring of vision, slurred speech \\
72 & F & B & $\begin{array}{l}\text { Dizziness, slurred speech, lightheaded, } \\
\text { and extreme numbness of her head }\end{array}$ \\
27 & F & B & Hypertension, slurred speech, numbness, asterixis \\
71 & F & R & Hypertension, dizzy, lightheaded \\
45 & F & B & Hypertension, pseudoseizure \\
73 & F & & Dizziness, blurring of vision, slurred speech \\
$1 \%$ Lidocaine & & B & Headache, tense and tight neck muscles \\
80 & F & B & Lightheaded \\
47 & M & B &
\end{tabular}

their experience with 5\% Lidocaine since then. We started using 5\% Lidocaine in our headache clinics in patients who had recurrent symptoms in spite of ONB with 1 and 2\% Lidocaine. We advanced their treatment to 5\% Lidocaine with the thought that this may produce prolonged effects as reported by Choi et al. Only 3 patients reported symptoms out of 173 ONB blocks with Lidocaine 1\%, which is consistent with other studies (Table 3). Our study showed a very slight (3\%) increase in AE with 5\% Lidocaine compared to $1 \%$ Lidocaine. Among the patients who had adverse effects with $1 \%$ Lidocaine, two were being injected for the first time and one patient was receiving an ONB for the second time. Among the patients who had adverse effects with 5\% Lidocaine, two had previously received ONB with $1 \%$, however, three patients were receiving ONB for the first time. Furthermore, of the 89 patients injected, 15 received ONB for the first time, of which 5 subjects had side effects. Of the 74 patients who received an ONB more than once, 3 had side effects. This data indicates that patients receiving injections for the first time were more likely to experience adverse effects. We speculate that repeated injections might have produced a tolerance, reducing the likelihood of adverse effects.

Based on our data which shows that none of the patients receiving 2\% Lidocaine had AEs, this may seem to be the "ideal" strength to use, but we cannot make that conclusion since the number of patients in the $2 \%$ Lidocaine group was much smaller than the other two groups. We suggest that there are multiple factors leading to adverse effects, with concentration being perhaps relatively minor, since some of our patients had AEs with $1 \%$ but tolerated 5\% Lidocaine injection very well.

Dizziness is a common side effect with local Lidocaine injections and the most commonly reported adverse effect in our case series (Table 3). Naja et al. [8] reported 47 patients who underwent ONB with a combination of Lidocaine, epinephrine, fentanyl, and clonidine of which 2 reported dizziness. Anthony et al. [9, 10] had the large series of 180 patients and they reported 8 patients with dizziness and gait uncertainty with ONB using 1\% Lidocaine and $160 \mathrm{mg}$ MP. Saadah et al. [11] also had a large study in which a total of 188 ONB injections were done with $1 \%$ Lidocaine and $12 \mathrm{mg}$ Betamethasone and reported dizziness for $1-2 \mathrm{~h}$ and injection site soreness for 1-2 days.

The side effect profile for Lidocaine when used for ONB was not listed in the Pharmaceutical Drug Reference, and on reviewing the package insert we did find dizziness, confusion, bradycardia and hypotension listed, but not elevation in blood pressure. In our study, the concentration and type of steroid remained the same for all patients, and therefore we believe that steroids were not likely the causation factor for the AEs, but this cannot be fully confirmed without comparing patients who received Lidocaine alone to those with a combination of Lidocaine and steroids.

Steroids have a mineral corticoid action and the intermittent hypertension developing within the few minutes of injection may be related to this and also given the close proximity of GON with the artery raises the possibility of arterial puncture, however, no reports were found on literature search. Patients who receive multiple blocks may need to be monitored for the development of a very rare side effect, Cushing's syndrome. Lavin et al. [12] reported a case of 39-year-old female who had six bilateral GON blocks over a period of 3 months developed signs of Cushing's syndrome with intermittent hypertension, severe muscle weakness, and fluid retention. Slurring of speech was observed in all our patients who developed intermittent hypertension and dizziness. Slurred speech is not listed as a side effect of local injection of Lidocaine or Depo-medrol in the package inserts.

Leinisch-Dahlke et al. [13] injected 15 tension headache patients, with prilocaine $1 \%$ and dexamethasone, and reported injection site pain in 3 and bradycardia in 1 patient during neck palpation. Ambrosini et al. reported local pain in two patients after injecting 13 patients for cluster 
Table 3 Review of occipital nerve block adverse events in literature

\begin{tabular}{|c|c|c|c|}
\hline Study & Population & Side effects & Medication injected \\
\hline Saadah, Taylor [11] & $\begin{array}{l}\text { Total } 188 \text { injections: (post- } \\
\text { traumatic, } 11 ; \text { tension, } 85 ; \\
\text { postinfectious, } 20 ; \\
\text { unclassifiable } 13 \text { ) }\end{array}$ & $\begin{array}{l}\text { Generally, dizziness for } \\
1-2 \mathrm{~h} \text {, injection site } \\
\text { soreness for } 1-2 \text { days }\end{array}$ & $\begin{array}{l}10 \mathrm{~mL} 1 \% \mathrm{LC}+12 \mathrm{mg} \mathrm{BM} \text {, divided } \\
\text { among ONs. Total volume } 12 \mathrm{cc} \text { per } \\
\text { injection set }\end{array}$ \\
\hline Anthony [9] & $\begin{array}{l}\text { Cervicogenic HA } \\
\text { LC + MP to } 180 \text { pts } \\
\text { MP to } 180 \mathrm{pts} \\
\text { LC during HA, } 50 \mathrm{pts} \\
\text { IM MP alone } \\
\text { Chronic cluster, } 20 \mathrm{pts} \\
\text { Migraine, } 20 \mathrm{pts}\end{array}$ & $\begin{array}{l}8 \text { pts—dizziness, gait } \\
\text { uncertainty }\end{array}$ & $\begin{array}{l}\text { 3-4 mL } 1 \% \mathrm{LC}+160 \mathrm{mg} \text { MP } \\
(4 \mathrm{~mL}) \text { as separate injection (in } \\
\text { thirds, with the needle directed } \\
\text { straight, medially, and laterally) } \\
5 \mathrm{~min} \text { later or, if pt was ictal, after } \\
\text { the LC aborted the HA. Area } \\
\text { massaged after steroid injection }\end{array}$ \\
\hline Leinisch-Dahlke et al. [13] & $\begin{array}{l}\text { Tension, failed or intolerant to } \\
\text { preventive therapy. } 15 \text { patients }\end{array}$ & $\begin{array}{l}\text { Injection site pain in } 3 . \\
\text { Bradycardia } 36 \mathrm{BPM}\end{array}$ & $\begin{array}{l}5 \mathrm{~mL} 1 \% \text { prilocaine }+4 \mathrm{mg} \mathrm{DM} \text {, } \\
\text { total volume } 6 \mathrm{~mL} \text { per injection set }\end{array}$ \\
\hline Ambrosini et al. [18] & Cluster, $10 \mathrm{pts}$ & Local pain in 2 patients & $\begin{array}{l}0.5 \mathrm{~mL} 2 \% \mathrm{LC}+17.72 \mathrm{mg} \mathrm{BM} \\
(12.46 \mathrm{BM} \text { dipropionate, long } \\
\text { acting, } 5.26 \mathrm{mg} \text { BM disodium } \\
\text { phosphate), total volume } 3 \mathrm{~mL}\end{array}$ \\
\hline Afridi et al. [14] & $\begin{array}{l}\text { Total } 116 \text { injections Migraine, } \\
\text { 57; Cluster; 22; New HA, 16; } \\
\text { HC, } 10 .\end{array}$ & 2 pts-focal alopecia & $3 \mathrm{~mL} 2 \% \mathrm{LC}+80 \mathrm{mg} \mathrm{MP}$ \\
\hline Naja et al. [8] & $\begin{array}{l}\text { Cervicogenic HA: } 47 \text { pts received } \\
\text { mean } 5.3 \text { (up to } 13 \text { ) injections }\end{array}$ & 2 pts—dizziness & $\begin{array}{l}3 \mathrm{~mL} \text { of the following } 10 \mathrm{~mL} \text { solution } \\
\text { to each nerve: } 3 \mathrm{~mL} 2 \% \mathrm{LC}, 3 \mathrm{~mL} \\
2 \% \mathrm{LC}+\text { epi, } 2.5 \mathrm{~mL} 0.5 \% \mathrm{BP} \\
0.5 \mathrm{~mL} \text { fentanyl } 50 \mu \mathrm{g} / \mathrm{mL}, 1 \mathrm{~mL} \\
\text { clonidine } 150 \mu \mathrm{g} / \mathrm{mL}\end{array}$ \\
\hline
\end{tabular}

$B$ bilateral, $B P$ bupivicaine, $B M$ Betamethasone, $H A$ headache, $I M$ intramuscular, $L C$ lidocaine, $L O N$ lesser occipital nerve, $M P$ methylprednisolone, $N$ none, $S M O$ symptomatic medication overuse, $T C$ triamcinolone

headaches with $2 \%$ Lidocaine. None of our patients reported injection site pain. Other rare side effects reported in literature with ONB include alopecia. Afridi et al. [14] reported focal alopecia in 2 patients out of 116 injections with $2 \%$ Lidocaine and $80 \mathrm{mg}$ methylprednisone. Cutaneous atrophy after corticosteroid injection ranges from 1 to $14 \%$ of patients and resolution is reported to occur in 6-7 months and may persist for 24 months[15, 16]. None of our patients reported these side effects, even though many of them had serial injections. To prevent this complication, injections should avoid leakage into the dermis.

Previous studies have failed to show that combining Lidocaine with steroid provided added benefit for ONB when compared to Lidocaine alone [17, 18]. However, these studies have different patient population, different steroid, different concentration, and there was lack of uniformity of technique. All our patients, even those who had adverse reaction to the injection reported response to injection. One patient who had received $1 \%$ Lidocaine and reported dizziness went onto receive 5\% Lidocaine without any adverse effects. The data from this study show that Lidocaine injections are generally safe and well-tolerated, the commonest side effect being dizziness.
The clinical implication of distinguishing the side effect profile of different strengths of Lidocaine includes proper choice of subjects and proper pre-procedure instructions. We observed that all our patients who had side effects were on an empty stomach, and therefore we suggest the patients not to fast prior to undergoing this procedure. Based on our observation that most patients who had side effects had received bilateral injections at the same time, we now recommend that patients, who need bilateral injections, receive them at least $15-30 \mathrm{~min}$ apart, or on different visits. We also suggest that vital signs should be routinely monitored for $30 \mathrm{~min}$ post-procedure.

Our study limitations include the small sample size, the lack of a patient group who received only Lidocaine injections without steroids, and that we did not investigate disease parameters (disease duration and severity of pain) or treatment outcomes in our patients.

In conclusion, our study will also help remind the clinician that several types of Lidocaine injections are available for headache patient, and it is important to separate each element to tailor individualized treatment. Further studies comparing different concentration of Lidocaine with and without additional steroids are needed to address 
differences in long-term and adverse effect profile of this procedure.

Acknowledgments We gratefully acknowledge Nerses Sanaossian M.D. for statistical analyses.

Conflict of interest None.

\section{References}

1. Tobin J, Flitman S. Occipital nerve blocks: when and what to inject? Headache 2009:1-12

2. Gawel MJ, Rothbart PJ (1992) Occipital nerve block in the management of headache and cervical pain. Cephalalgia 12:9-13

3. Sahai-Srivastava S, Macwan S (2004) Atypical facial neuralgia. Pract Pain Manag 4(6):49-52

4. Sahai-Srivastava S, Zheng L(2009) Occipital neuralgia with and without migraines: differences in pain characteristics and risk factors. Cephalalgia 29(suppl 1). Abstract

5. Dash KS, Janis JE, Guyuron B (2005) The lesser and third occipital nerves and migraine headaches. Plast Reconstr Surg 115:1752-1758

6. Headache Classification Subcommittee of the International Headache society (2004) The international classification of headache disorders, 2nd edn. Cephalalgia 24(Suppl 1):9-160

7. Choi YK, Liu J (1998) The use of $5 \%$ lidocaine for prolonged analgesia in chronic pain patients: a new technique. Reg Anesth Pain Med 23:3-6

8. Naja ZM, El-Rajab M, Al-Tannir MA, Ziade FM, Tawfik OM (2006) Repetitive occipital nerve blockade for cervicogenic headache: expanded case report of 47 adults. Pain Pract 6:278-284

9. Anthony M (2000) Cervicogenic headache: prevalence and response to local steroid therapy. Clin Exp Rheumatol 18:S59 S64

10. Anthony M (1992) Headache and the greater occipital nerve. Clin Neurol Neurosurg 94:297-301

11. Saadah HA, Taylor FB (1987) Sustained headache syndrome associated with tender occipital nerve zones. Headache 27:201-205

12. Lavin PJ, Workman R (2001) Cushing syndrome induced by serial occipital nerve blocks containing corticosteroids. Headache 41:902-904

13. Leinisch-Dahlke E, Jürgens T, Bogdahn U, Jakob W, May A (2005) Greater occipital nerve block is ineffective in chronic tension type headache. Cephalalgia 25:704-708

14. Afridi SK, Shields KG, Bhola R, Goadsby PJ (2006) Greater occipital nerve injection in primary headache syndromes-prolonged effects from a single injection. Pain 122:126-129

15. Louis DS, Hankin FM, Eckenrode JF (1986) Cutaneous atrophy after corticosteroid injection. Am Fam Physician 33:183-186

16. Jacobs MB (1986) Local cutaneous atrophy after corticosteroid injection. Postgrad Med 80:159-160

17. Ashkenazi A, Matro R, Shaw JW, Abbas MA, Silberstein SD (2008) Greater occipital nerve block using local anesthetics alone or with triamcinolone for transformed migraine: a randomized comparative study. J Neurol Neurosurg Psychiatry 79:415-417

18. Ambrosini A, Vandenheede M, Rossi P, Aloj F, Sauli E, Pierelli F, Schoenen J (2005) Suboccipital injection with a mixture of rapid- and long-acting steroids in cluster headache: a doubleblind placebo-controlled study. Pain 118(1):92-96 